\title{
Methods for preserving fertility in young women suffering from cancer: some aspects of ovarian tissue cryopreservation
}

\author{
Zakova $\mathrm{J}^{1}$, Sedlackova $\mathrm{M}^{2}$, Polak $\mathrm{S}^{3,4}$, Dumkova $\mathrm{J}^{2}$, Ventruba $\mathrm{P}^{1}$, Crha $\mathrm{I}^{1}$ \\ Department of Gynecology and Obstetrics, Faculty of Medicine, Masaryk University, Brno, Czech Republic. \\ stefan.polak@fmed.uniba.sk
}

Dear Editor-in-Chief, Bratislava Medical Journal,

A great interest increases in revealing the pathogenesis of oncologic diseases by experimental tumorigenesis to perform early diagnosis and treatment strategies (1). New methods of cancer therapy, often aggressive, now bring questions such as: how to prevent the decrease in ovarian function and fertility in young women suffering from cancer. The purpose of our paper is to review shortly the current methods. Our preliminary ultrastructural study shows that the method of cryopreservation of human ovarian tissue causes minimal structural changes in primordial and primary ovarian follicles.

The human ovarian cortex is populated by a finite store of primordial germ cells. They migrate during the early fetal life from the wall of the yolk sac into the developing ovaries (forming from a paired indifferent gonad). The germ cells of endodermal origin differentiate later into oogonia. The oogonia in ovary are surrounded by stromal cells derived from coelomic epithelium, and develop into follicular or granulose cells. The follicular cells are flattened at the beginning and later, during the ovarian cycle they become polyhedral repeated divisions of oogonia as well as follicular cells form the immature primordial follicle. These follicles are continuously involved in the growth of antral follicles, but just a few of them are preferred to mature until ovulation (2, $3)$. In humans and in other primates as well, only one single follicle reaches the pre-ovulatory stage each cycle; most follicles fail in this maturation scheme and die in the apoptotic process termed atresia (4). A female child is born with 1-2 million primordial follicles in its ovarian cortex. The number of follicles reduces by speed of 1,000 follicles per month, and at menarche, there are 400,000 follicles available. Even though menopause marks a definitive end of

${ }^{1}$ Department of Gynecology and Obstetrics, Faculty of Medicine, Masaryk University, Brno, Czech Republic, ${ }^{2}$ Department of Histology and Embryology, Faculty of Medicine, Masaryk University, Brno, Czech Republic, ${ }^{3}$ Department of Histology and Embryology, Faculty of Medicine, Comenius University, Bratislava, Slovakia, and ${ }^{4}$ University Centrum of Reproductive Medicine of the 1st Department of Gynecology and Obstetrics, University Hospital in Bratislava, Bratislava, Slovakia

Address for correspondence: S. Polak, MD, PhD, Department of Histology and Embryology, Faculty of Medicine, Comenius University, Sasinkova 4, SK-811 08 Bratislava, Slovakia.

Phone: +421.2.59357236 the reproductive lifespan with exhaustion of follicles, the female fertility already initiates to decrease at the age of 30 years. By the age of 40 years, the incidence of significant problems with human fertility is already marked, in both spontaneous and assisted conceptions $(5,6)$. Fertility difficulties are particularly caused by a stable injurious effect of environment (7).

The number of 450 matured follicles approximately is a sufficient amount for the whole reproductive life of a female. But some anticancerous treatment schemes are excessively aggressive and besides the successful cancer-treating effect in many young women, they lose both ovarian endocrine function and fertility (8). Ionizing radiation and the majority of alkylating agents can often induce early ovarian failure, rendering the patient infertile. For instance, intensive chemotherapy and radiotherapy, prior to bone marrow transplantation, used in the treatment of some hematologic diseases, can also result in ovarian failure (9). The precise mechanism of follicular damage induced by chemo or radiotherapy is not yet well understood. Ovarian impairment caused by radiotherapy depends on the position of abdominal radiotherapy field. Moreover, there are no human studies considering the quality of oocytes and embryos derived from a prior course of chemotherapy (10).

Methods of preserving the fertility in young women can be divided into three cryopreservative methods, namely those preserving the embryo, mature oocytes, or ovarian tissue. Cancer patients can undergo follicle aspiration followed by in vitro fertilization and have their embryos stored in freeze bank prior to the treatment, or during a suitable break in it (11). In 1985, Mohr and Trounson (12) report about the first successful delivery after the frozen human embryo transfer. Today, the rate of achievement following the procedure is high. Unfortunately, barely a limited number of oocytes can be collected and the technique is not generally applicable in all cancer patients. For example, ovarian stimulation is contraindicated in malignant estrogen-sensitive tumors such as carcinoma of breast. The method seems to be inappropriate for prepubertal girls and often unacceptable to single women who do not wish to use donor spermatozoa (5). According to several reports $(13,14)$, cryopreservation increases the incidence of monozygotic twinning, although other reports indicate that no such relationship exists $(15,16)$. Repiska et al $(17)$ described a very rare case of octuplet pregnancy following cryo-embryo transfer. 


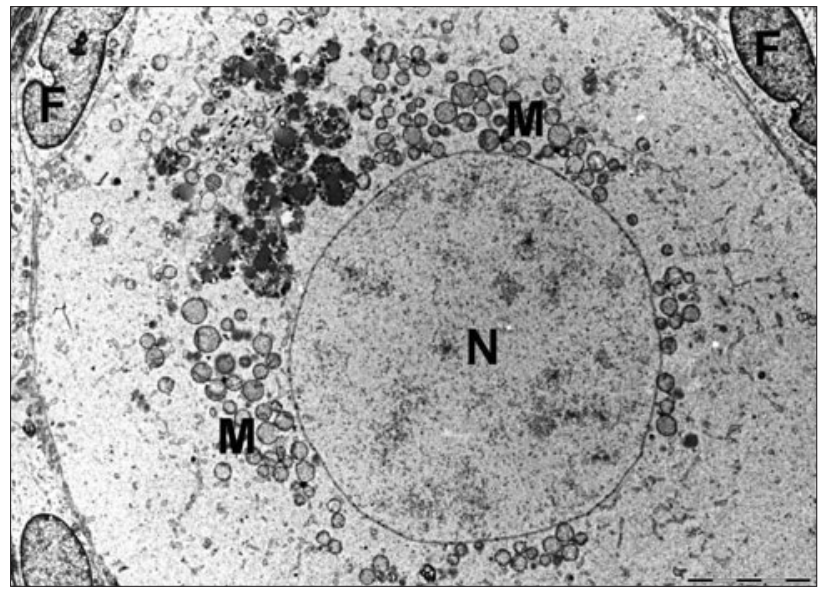

Fig. 1. Primordial follicle from a "fresh" ovarian cortex. Large, pale nucleus $(\mathrm{N})$ and perinuclear distribution of organelles, mostly mitochondria (M). Flattened follicular cells (F) surrounding oocyte (TEM, line in Fig. $=5 \mu \mathrm{m})$.

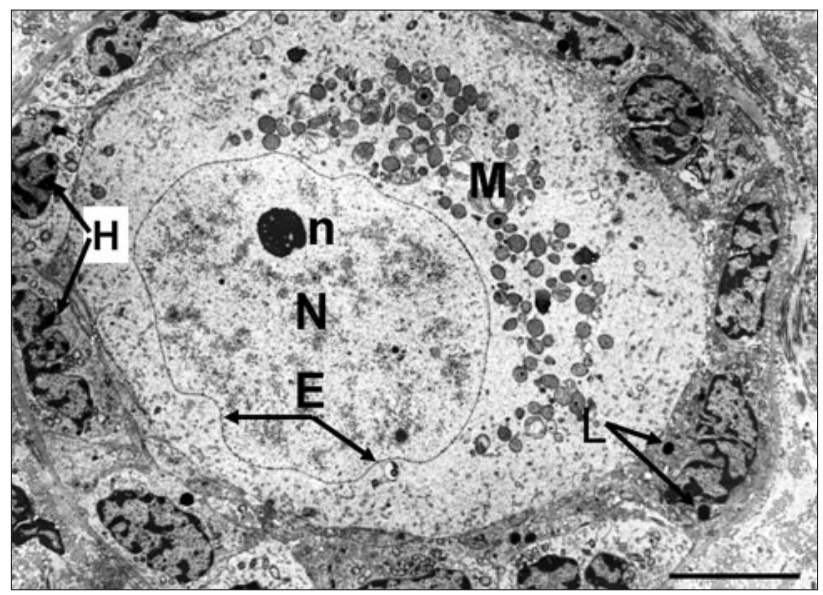

Fig. 2. Primary follicle after cryopreservation with minimal morphological alterations. Large and pale nucleus $(\mathrm{N})$ with marked nucleolus (n). The nuclear envelope (E) of oocyte is undulated. Follicular cells have a higher accumulation of heterochromatine $(\mathrm{H})$ in nuclei, and more lipid droplets (L) in cytoplasm (TEM, line in Fig. $=5 \mu \mathrm{m}$ ).

Human mature oocyte cryopreservation represents a valid alternative to legal, moral and religious problems encountered in association with embryo freezing since it does not require the presence of a male partner and thus has an undoubtedly positive impact on assisted reproduction techniques. The first birth after human oocyte cryopreservation was reported by Chen (18) in 1986. The pregnancy rates after embryo transfer from frozen oocytes stay still very low ( $1 \%$ to $5 \%$ ) even though such a long period had gone. There are various reasons for this limited success, namely low oocyte survival degree, low fertilization rate after traditional in vitro fertilization, high incidence of polypoidy, and poor developmental ability of embryos (10). Recently, the first successful fertility preservation with frozen mature oocytes in cancer patient has been reported by Yang et al in 2007 (19).

The idea of ovarian tissue cryopreserving as a whole is based on the invention that the primordial follicles protected by ovarian

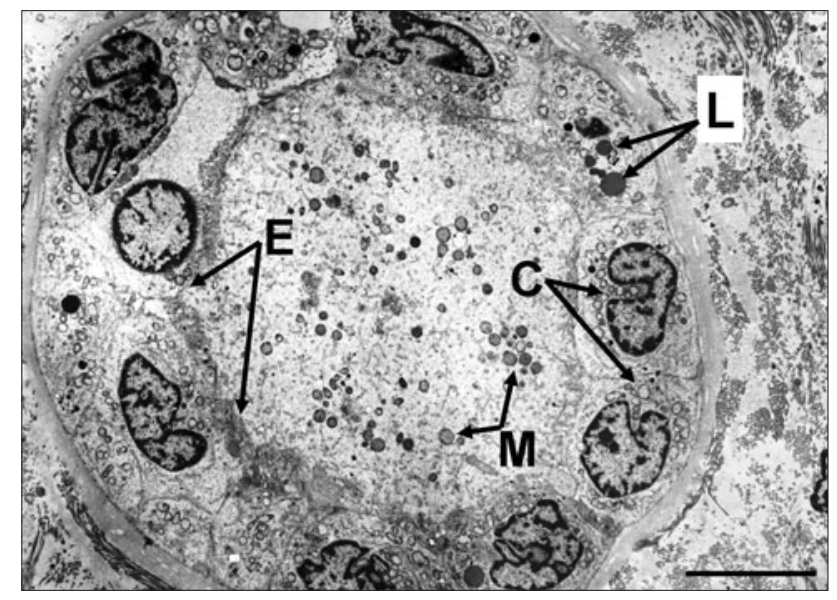

Fig. 3. Primary follicle after cryopreservation with prominent morphological alterations. In cytoplasm of oocyte there are mitochondria (M), the oolema is more undulated and interrupted in more places. The cytoplasm of follicular cells is vacuolated $(\mathrm{C})$ and contains lipid and lipofuchsine droplets (L) (TEM, line in Fig. = $5 \mu \mathrm{m})$.

cortex are more resistant to cryo-injury than the mature oocytes are. The oocytes in primordial follicles of ovarian cortex are small, not yet completely developed, with few organelles, with no covering of zona pellucida, and are relatively metabolically quiescent and undifferentiated in comparison with mature oocytes (20). But the greatest risk with ovarian tissue cryopreservation is the possibility that by autografting a frozen-thawed ovarian strip it is possible to re-convey a tumor harbored within the ovary (21). In 2004, Donnez et al (22) described a first live birth after orthopic transplantation of cryopreserved ovarian tissue. Their findings suggest that cryopreservation of ovarian tissue should be offered generally to all young women with cancer diagnosis. Other authors assume that it is too soon to recommend this technique on a routine basis (23).

Numerous morphological works deal with the ultrastructural characteristics of frozen and thawed human mature oocytes. Most of them describe a variety of ultrastructural alterations, like an increased density of the inner part of zona pellucida, in some cases a delamination of zona pellucida, or vacuolization of oocyte cytoplasm (24-27). Nevertheless, so far we have found only three studies to be dealing with ultrastructural changes of oocytes and follicular cells after ovary cryopreservation of which two were conducted in humans (28-30) and one in mice (31).

In our preliminary study, we investigated frozen and thawed tissue stripes of ovarian cortex after laparoscopy in a 21-year-old woman. A small sample of ovarian tissue was immediately fixed with $3 \%$ glutaraldehyde, post-fixed with $1 \% \mathrm{OsO}_{4}$ in phosphate buffering solution and embedded in Durcupan ACM. The ultrathin sections were contrasted with uranyl acetate and lead citrate. The rest of ovarian tissue was frozen and stored in 1,2-propandiole for two months. After thawing in $37^{\circ} \mathrm{C}$ water bath, the tissue was prepared for transmission electron microscopic examination with the same method.

We found numerous primordial and primary follicles in tissue samples from "fresh" ovarian tissue, as well as from the frozen and thawed tissue. The "fresh" primordial follicle as seen in 
Fig 1 normally contains an oocyte with a large pale nucleus, and perinuclear distribution of organelles (mostly mitochondria). The follicular cells have also large and pale nuclei with abundant euchromatine. After the freezing and thawing procedure the most remarkable changes we observed surprisingly not in oocytes but in follicular cells and other stromal cells. These changes in morphology of follicular cells include intense condensation of heterochromatine in nuclei, changes in mitochondrial morphology and an increase in lipid droplets density (Figs 2 and 3). Most of frozen and thawed oocytes had entire oolema as well as nuclear envelope. The ultrastructure picture of oocytes with normal morphological features and perinuclear distribution of organelles shows that these oocytes seem to be viable. We assume, that cryopreservation of ovarian tissue represents an effective alternative or an addition to cryopreservation of embryos or oocytes for women at risk of premature ovarian failure due to chemotherapy.

\section{References}

1. Valaskova Z, El-Hassoun O, Galfiova P, Jakubovsky J, Danihel L, Hulin I. Perspective and complexity of experimental cancer study. The secrets of tumorigenesis. (To the Gupta's, Chaffer's and Weinberg's "perspectives” and to the Nurse's “horizons”). Bratisl Lek Listy 2010; 111 (1): 9-12.

2. Jiménez R. Ovarian organogenesis in mammals: mice cannot tell us everything. Sex Dev 2009; 3 (6): 291-301.

3. Richards JS, Pangas SA. The ovary: basic biology and clinical implications. J Clin Invest 2010; 120 (4): 963-972.

4. Gougeon A. Regulation of ovarian follicular development in primates: facts and hypotheses. Endocr Rev 1996; 17: 121-155.

5. Newton H. The cryopreservation of ovarian tissue as a strategy for preserving the fertility of cancer patients. Hum Reprod Update 19984 (3): 237-247.

6. Perheentupa A, Huhtaniemi I. Aging of the human ovary and testis. Mol Cell Endocrinol 2009; 299 (1): 2-13.

7. Ray B, Potu BK. Ovarian folliculogenesis: Detrimental effect of prenatal exposure to cyclophosphamide: a preliminary study. Bratisl Lek Listy 2010; 111 (7): 369-372.

8. Fabbri R, Pasquinelli G, Bracone G, Orrico C, Di Tommaso B, Venturoli S. Cryopreservation of human ovarian tissue. Cell Tissue Bank 2006; 7: 123-133.

9. Thomas ED. Bone marrow transplantation: a review. Semin Hematol 1999; 10: 95-103.

10. Tao T, Del Valle A. Human oocyte and ovarian tissue cryopreservation and its application. J Assist Reprod Genet 2008; 25: 287-296.

11. Brown JR, Modell E, Obasaju M, King YK. Natural cycle in vitro fertilization with embryo cryopreservation prior to chemotherapy for carcinoma of the breast. Hum Reprod 1996; 11: 197-199.

12. Mohr LR, Trounson AO. Cryopreservation of human embryos. Ann NY Acad Sci 1985; 442: 536-543.

13. Toledo MG. Is there increased monozygotic twinning after assisted reproductive technology? Aust N Z J Obstet Gynaecol 2005; 45: 360-364.

14. Faraj R, Evbuomwan I, Sturgiss S, Aird I. Monozygotic triplet pregnancy following egg donation and transfer of single frozen-thawed embryo. Fertil Steril 2008; 89: 1260.e9-12.
15. Alikani M, Cekleniak, NA, Walters E, Cohen J. Monozygotic twinning following assisted conception: an analysis of 81 consecutive cases. Hum Reprod 2003; 18: 1937-1943.

16. Blickstein I, Jones C, Keith LG. Zygotic-splitting rates after single-embryo transfers in in vitro fertilization. N Engl J Med 2003; 348: 2366-2367.

17. Repiska V, Lehocký I, Danišovič L', Varga I, Böhmer D, Danihel L', Galbavý Š. Octuplet pregnancy following intracytoplasmic sperm injection and cryo embryo transfer. Med Sci Monit 2009; 15 (9): CS143-147.

18. Chen C. Pregnancy after human oocyte cryopreservation. Lancet 1986; 2: 884-886.

19. Yang D, Brown SE, Nguyen K, Reddy V, Brubaker C, Winslow KL. Live birth after the transfer of human embryos developed from cryopreserved oocytes harvested before cancer treatment. Fertil Steril 2007; 87: 1469.

20. Nugent D, Meirow D, Brook PF, Aubard Y, Gosden RG. Transplantation in reproductive medicine: previous experience, present knowledge and future prospects. Hum Reprod Updat 1997; 3: 267-280.

21. Sonmezer M, Shamonki MI, Oktay K. Ovarian tissue cryopreservation: benefits and risks. Cell Tissue Res 2005; 322: 125-132.

22. Donnez J, Dolmans MM, Demylle D, Jadoul P, Pirard C, Squifflet J, Martinez-Madrid B, van Langendonckt A. Livebirth after orthopic transplantation of cryopreserved ovarian tissue. Lancet 2004; 364: 1405-1410.

23. Oktay K, Tilly J. Correspondance: Livebirth after cryopreserved ovarian tissue autotransplantation. Lancet 2004; 364: 2091-2092.

24. Nottola SA, Coticchio G, De Santis L, Macchiarelli G, Maione M, Bianchi S, Iaccarino M, Flamigni C, Borini A. Ultrastructure of human mature oocytes after slow cooling cryopreservation with ethylene glycol. Reprod Biomed Online 2008; 17 (3): 368-377.

25. Nottola SA, Macchiarelli G, Coticchio G, Bianchi S, Cecconi S, De Santis L, Scaravelli G, Flamigni C, Borini A. Ultrastructure of human mature oocytes after slow cooling cryopreservation using different sucrose concentrations. Hum Reprod 2007; 22 (4): 1123-1133.

26. Nottola SA, Coticchio G, Sciajno R, Gambardella A, Maione M, Scaravelli G, Bianchi S, Macchiarelli G, Borini A. Ultrastructural markers of quality in human mature oocytes vitrified using cryoleaf and cryoloop. Reprod Biomed Online 2009; Suppl 3: 17-27.

27. Coticchio G, Borini A, Distratis V, Maione M, Scaravelli G, Bianchi V, Macchiarelli G, Nottola SA. Qualitative and morphometric analysis of the ultrastructure of human oocytes cryopreserved by two alternative slow cooling protocols. J Assist Reprod Genet 2010; 27 (4): 131-140.

28. Camboni A, Martinez-Madrid B, Dolmans MM, Amorim CA, Nottola SA, Donnez J, Van Langendonckt A. Preservation of fertility in young cancer patients: contribution of transmission electron microscopy. Reprod Biomed Online 2008; 17 (1): 136-150.

29. Fabbri R, Pasquinelli G, Bracone G, Orrico C, Di Tommaso B, Venturoli S. Cryopreservation of human ovarian tissue. Cell Tissue Bank 2006; 7 (2): 123-133.

30. Fabbri R, Pasquinelli G, Bracone G, Orrico C, Paradisi R, Seraccioli R, Venturoli S. Fetal calf serum versus human serum: ultrastructural evaluation of protein support influence on human ovarian tissue cryopreservation. Ultrastruct Pathol 2006; 30 (4): 253-260.

31. Nisolle M, Casanas-Roux F, Qu J, Motta P, Donnez J. Histologic and ultrastructural evaluation of fresh and frozen-thawed human ovarian xenografts in nude mice. Fertil Steril 2000; 74 (1): 122-129.

Received October 18, 2010. Accepted January 9, 2012. 